\title{
Correction to: Agglomerative Algebras
}

\section{Jeremy Goodman ${ }^{1}$}

Published online: 14 October 2020

(C) Springer Nature B.V. 2020

Correction to: Journal of Philosophical Logic

https://doi.org/10.1007/s10992-018-9488-8

The original version of the article unfortunately contained a few mistakes. In Proposition 60, " $Y=V$ " should be " $Y=\emptyset$ " and " $\Pi(V)$ " should be " $\mathcal{P}(V)$ ".

In Remark 62, "In a partition agglomerative algebra" should be "In any partition agglomerative algebra such that, for all $\langle X, \pi\rangle \in A$ and $S \subseteq \pi$, $\langle\bigcup S, \pi\rangle \in A$ ". The second sentence of the remark is also false: the relevant fact is not illustrated by Example 61, although it would be illustrated by a simplification of that example in which $\mathcal{L}$ did not contain the constant $F$.

In Definitions 66 and 68 "EQUIVALENCE" should be "TRANSITIVITY".

Publisher's Note Springer Nature remains neutral with regard to jurisdictional claims in published maps and institutional affiliations.

The online version of the original article can be found at https://doi.org/10.1007/s10992-018-9488-8

Jeremy Goodman

goodman.jeremy@gmail.com

1 University of Southern California, 3709 Trousdale Parkway, Los Angeles, CA 90089, USA 